\title{
Relation between urine soluble trigerring receptor expressed on myeloid cells (sTERM-1 ) and blood culture for diagnosis of late onset sepsis in neonates A.S.Elsayed ${ }^{1}$, Y.M.Esmail ${ }^{2}$, E.H.Assar ${ }^{1}$, and M.I.Kora ${ }^{1}$ \\ ${ }^{1}$ Pediatrics, Dept., Faculty of Medicine, Benha Univ., Benha, Egypt \\ ${ }^{2}$ Clinical pathology, Dept., Faculty of Medicine, Benha Univ., Benha, Egypt
}

E-Mail: Manal Ibrahim@yahoo.com

\begin{abstract}
Background: The sepsis gold standard is to identify the blood-growing agent. However, the production of a pathogen is not feasible for various reasons, even in the finest facilities. The purpose of this research was to identify the relationship between myeloid cell myeloid cell (STREM-1)-soluble trigger receptor and blood culture to diagnose late onset septicism. Methods: 100 cases from newborn intensive care units (NICU) divided into the following categories were included in this comparative case/check research. Group 1: 60 patients with positive blood culture sepsis included, Group 2: 40 patients with negative blood culture sepsis and Group 3: 100 patients with healthy neonate. All of the newborns included have been submitted to comprehensive history, clinical and laboratory tests of CBC, CRP and urine sTREM-1. Outcome: $60(60 \%)$ instances of positive blood culture were 83,28 $\pm 6,17 \mathrm{pg} / \mathrm{ml}$ of the mean uTREM1, compared to $51,19 \pm 19,47 \mathrm{pg} / \mathrm{ml}$ of the negative crop group and 78,22 $\pm 0,25 \mathrm{pg} / \mathrm{ml}$ of the checks, $\mathrm{p}<0,001$. ROC curve was used to evaluate uTREM's diagnostic results for positive blood culture, uTREM1 was able to forecast positive AUC $=0.999(\mathrm{p}<0.001), \mathrm{CI}(0.990-1)$. The sensitivity was 98.33 percent at a cut-off of $>72 \mathrm{pg} / \mathrm{ml}$, the specificity was 95 percent, 96.7 percent and 97.4 percent. Conclusion: Our findings support the use of uTREM-1 in newborn sepsis as a potentially simple and reliable diagnostic while awaiting results and results in culture.
\end{abstract}

Keywords: sTERM-1, blood culture, sepsis, neonates.

\section{Introduction}

In both affluent and developing nations, neonatal sepsis is a significant cause of disease and mortality. The World Health Organization reports that about 4 million babies die from septic illness each year, with a significant percentage of those fatalities occurring in poor countries and infections being high on the list of causes of disease [1].

The sepsis gold standard is to isolate the agent in blood culture. However, the production of a pathogen is not feasible for various reasons, even in the finest facilities. Studies have thus been conducted on the diagnosis of newborn sepsis in both blood culture and clinical and laboratory-assisted diagnostic methods [2].

Ideally, assistive diagnostic techniques should be able to detect sepsis at a high rate so that sepsis is excluded if it doesn't exist. However, because none of the screen tests are sufficiently sensitive to infection, it is essential that a clinical assessment be conducted for diagnosis and practical therapy. Biomarkers are often utilised in septic disease diagnosis and monitoring[3].

Many indicators have been employed in research, including as acute stage reactants, pro and antiinflammatory mediators, and surface cell antigens. [4].

The myeloid cell receptor (TREM-1) triggers a glycoprotein that belongs to the immunoglobulin family. TREM-1 is an essential receptor in the event of inflammation and the diagnosis of sepsis, increased by neutrophils and monocytes [5].

This glycoprotein is regulated by neutrophils after interaction with lipopolysaccharides and lipopolytic macrophages and gram-positive bacteria, gram-negative bacteria or fungus. The neutrophil count increases during inflammation and thus increases TREM-1 levels in the event of sepsis. Moreover, the failure to raise TREM-1 levels in noninfectious cases, as shown in recent adult investigations, indicates that the diagnosis of sepsis by TREM-1 may be especially sensitive [6].

TREM-1 (sTREM-1) soluble form is secreted by active phagocytes and is present in all bodily fluids. This soluble shape is strongly linked to infection. Many adult investigations of sTREM-1 have been conducted, including elevated serum sTREM-1 levels in bodily fluid samples for different illnesses and conditions [7].

This result indicates that STREM-1 may be a diagnostic for identifying preterm babies with sepsis. Studies have also been conducted in neonates to identify sepsis at Serum sTREM-1 levels. While adult studies indicate that urine sTREM-1 levels may predict sepsis, it is unclear if urine sTREM-1 levels can predict sepsis in preterm babies. Diagnosis of sepsis in preterm babies is challenging, and this is essential in poor countries in particular [8].

The purpose of this study was to identify the relationship between myeloid-cell myeloid-solubles triggering receptors (STREM-1) and blutineering for diagnosis of late onset septic sepsis at Benha University Hospital.

\section{Patients and methods}

This comparative case/ control study was conducted on patients attending Benha university hospital and Benha Children Hospital during the period from December 2018 to December 2020.

Approval of the study protocol by ethical scientific committee of Benha university hospital and benha children hospital was obtained \& informed conscent was obtained from the parents before enrollment in the study. 
2.1. The study was conducted on the following groups

It included 100 cases collected from the neonatal intensive care unit (NICU) of Benha university hospital and Benha Children Hospital (BENCH) in the period from December 2018 to December 2020 in the following groups :

\section{Group 1(Positive blood culture group) :-}

\subsection{Inclusion criteria}

- Both sexes will be included.

- Post natal age more than 5 days.

- Neonates with clinically suspected neonatal sepsis

- Preterm and full term neonates

- Positive blood culture for sepsis

- The signs of sepsis are non-specific and include:

- Body temperature changes

- Breathing problems

- Diarrhea

- Low blood sugar (Hypoglycemia)

- Poor activity

- Poor sucking

- Seizures

- Bradycardia

- Abdominal distension

- Vomiting

- Yellow skin (Jaundice)

2.3. Exclusion criteria

- Neonates presenting with renal malformations, chromosomal abnormalities and congenital infection .

- Neonates who have perinatal asphyxia, sedation.

Group 2 (Negative blood culture group):-

As group 1 but with negative blood culture for sepsis .

Group 3(control group) :-

It included 100 Neonate selected from Benha university hospital and Benha Children Hospital they would be healthy Neonate, both sexes (male- Female), age (> 5 days) as a control group.
All included neonates were subjected to full history taking, complete clinical examination, and laboratory investigations of $\mathrm{CBC}, \mathrm{CRP}$, blood culture and urine sTREM-1.

\subsection{Statistical analysis of the data}

Data were fed to the computer and analyzed using IBM SPSS software package version 20.0. (Armonk, NY: IBM Corp) Qualitative data were described using number and percent. The Kolmogorov-Smirnov test was used to verify the normality of distribution Quantitative data were described using range (minimum and maximum), mean, standard deviation, median and interquartile range (IQR). Significance of the obtained results was judged at the $5 \%$ level. The used tests were done; Chi-square test; For categorical variables, to compare between different groups. Monte Carlo correction; Correction for chi-square when more than $20 \%$ of the cells have expected count less than 5, Ftest (ANOVA); For normally distributed quantitative variables, to compare between more than two groups, and Post Hoc test (Tukey) for pairwise comparisons, Kruskal Wallis test; For abnormally distributed quantitative variables, to compare between more than two studied groups, and Post Hoc (Dunn's multiple comparisons test) for pairwise comparisons, Receiver operating characteristic curve (ROC); It is generated by plotting sensitivity (TP) on $\mathrm{Y}$ axis versus 1 -specificity (FP) on $\mathrm{X}$ axis at different cut off values. The area under the ROC curve denotes the diagnostic performance of the test. Area more than $50 \%$ gives acceptable performance and area about $100 \%$ is the best performance for the test. The ROC curve allows also a comparison of performance between two tests.

\section{Results}

There was no statistical difference between the three studied groups according to gestational age,postnatal age and weight at diagnosis. Table 1

Table (1) Comparison between the three studied groups according to different parameters.

\begin{tabular}{|c|c|c|c|c|c|}
\hline & \multicolumn{2}{|c|}{ Cases $(n=100)$} & \multirow[b]{2}{*}{$\begin{array}{l}\text { Control (group III) } \\
\quad(\mathbf{n}=\mathbf{1 0 0})\end{array}$} & \multirow[b]{2}{*}{$\begin{array}{l}\text { Test of } \\
\text { Sig. }\end{array}$} & \multirow[b]{2}{*}{$\mathbf{p}$} \\
\hline & $\begin{array}{c}\text { Positive blood culture } \\
\text { (group I) } \\
(\mathbf{n}=\mathbf{6 0})\end{array}$ & $\begin{array}{c}\text { Negative blood culture } \\
\text { (group II) } \\
(\mathbf{n}=\mathbf{4 0})\end{array}$ & & & \\
\hline \multicolumn{6}{|l|}{$\begin{array}{l}\text { Gestational age } \\
\text { weeks }\end{array}$} \\
\hline Min. - Max. & $27.0-40.0$ & $27.0-40.0$ & $32.0-40.0$ & \multirow{3}{*}{$\begin{array}{c}\mathrm{F}= \\
2.975\end{array}$} & \multirow{3}{*}{0.053} \\
\hline Mean \pm SD. & $34.55 \pm 3.32$ & $35.57 \pm 2.33$ & $35.42 \pm 1.81$ & & \\
\hline Median (IQR) & $34.50(32.0-37.0)$ & $36.0(35.0-37.0)$ & $36.0(35.0-37.0)$ & & \\
\hline \multicolumn{6}{|c|}{$P$ natal age (days) } \\
\hline Min. - Max. & $4.0-54.0$ & $6.0-54.0$ & $6.0-24.0$ & \multirow{3}{*}{$\begin{array}{c}\mathrm{H}= \\
5.778\end{array}$} & \multirow{3}{*}{0.056} \\
\hline Mean \pm SD. & $15.20 \pm 9.51$ & $16.78 \pm 12.83$ & $11.28 \pm 4.42$ & & \\
\hline Median (IQR) & $11.50(8.50-21.0)$ & $12.0(8.0-18.50)$ & $10.0(8.0-13.0)$ & & \\
\hline \multicolumn{6}{|l|}{ Wt. at diag } \\
\hline Min. - Max. & $1.50-4.80$ & $1.50-5.0$ & $2.0-4.0$ & \multirow{3}{*}{$\begin{array}{c}\mathrm{F}= \\
2.394\end{array}$} & \multirow{3}{*}{0.094} \\
\hline Mean \pm SD. & $2.96 \pm 0.83$ & $3.20 \pm 0.66$ & $3.20 \pm 0.65$ & & \\
\hline Median (IQR) & $2.75(2.28-3.80)$ & $3.20(2.90-3.50)$ & $3.30(3.0-3.70)$ & & \\
\hline
\end{tabular}

IQR: Inter Quartile Range

F: F for ANOVA test

$\mathrm{H}$ : $\mathrm{H}$ for Kruskal Wallis test 
Table (2) Comparison between the three studied groups according to CBC and BAND.

\begin{tabular}{|c|c|c|c|c|c|}
\hline & \multicolumn{2}{|c|}{ Cases $(n=100)$} & \multirow[b]{2}{*}{$\begin{array}{c}\text { Control (group III) } \\
\quad(\mathbf{n}=\mathbf{1 0 0})\end{array}$} & \multirow[b]{2}{*}{$\begin{array}{l}\text { Test of } \\
\text { Sig. }\end{array}$} & \multirow[b]{2}{*}{$\mathbf{p}$} \\
\hline & $\begin{array}{c}\text { Positive blood culture } \\
\text { (group I) } \\
(\mathbf{n}=\mathbf{6 0})\end{array}$ & $\begin{array}{c}\text { Negative blood culture } \\
(\text { group II) } \\
(\mathrm{n}=\mathbf{4 0})\end{array}$ & & & \\
\hline \multicolumn{6}{|l|}{ TLC } \\
\hline Min. - Max. & $2.50-20.0$ & $5.0-12.0$ & $7.0-10.0$ & \multirow{3}{*}{$\begin{array}{c}\mathrm{H}= \\
0.338\end{array}$} & \multirow{3}{*}{0.844} \\
\hline Mean \pm SD. & $9.17 \pm 4.68$ & $8.34 \pm 1.85$ & $8.20 \pm 1.02$ & & \\
\hline Median (IQR) & $8.0(6.0-12.0)$ & $8.0(7.0-10.0)$ & $8.0(7.0-9.0)$ & & \\
\hline \multicolumn{6}{|l|}{ PLT } \\
\hline Min. - Max. & $10.0-390.0$ & $115.0-415.0$ & $250.0-500.0$ & \multirow{3}{*}{$\begin{array}{c}H= \\
101.81^{*}\end{array}$} & \multirow{3}{*}{$<0.001^{*}$} \\
\hline Mean \pm SD. & $148.9 \pm 103.2$ & $276.4 \pm 72.40$ & $364.9 \pm 73.13$ & & \\
\hline Median (IQR) & $132.5(60.0-212.0)$ & $285.0(230.0-313.0)$ & $359.0(300.0-450.0)$ & & \\
\hline $\begin{array}{l}\text { Sig. bet. Grps. } \\
\text { HG }\end{array}$ & \multicolumn{5}{|c|}{$\mathrm{p}_{1}<0.001^{*}, \mathrm{p}_{2}<0.001^{*}, \mathrm{p}_{3}<0.001^{*}$} \\
\hline Min. - Max. & $6.0-14.0$ & $10.0-15.0$ & $13.0-17.0$ & \multirow{4}{*}{$\begin{array}{c}F= \\
207.531^{*}\end{array}$} & \multirow{4}{*}{$<0.001^{*}$} \\
\hline Mean \pm SD. & $10.0 \pm 1.84$ & $12.68 \pm 1.54$ & $14.96 \pm 1.22$ & & \\
\hline Median (IQR) & $10.0(9.0-11.0)$ & $12.50(11.50-14.0)$ & $15.0(14.0-16.0)$ & & \\
\hline $\begin{array}{l}\text { Sig. bet. Grps. } \\
\text { HCT }\end{array}$ & \multicolumn{3}{|c|}{$\mathrm{p}_{1}<0.001^{*}, \mathrm{p}_{2}<0.001^{*}, \mathrm{p}_{3}<0.001^{*}$} & & \\
\hline Min. - Max. & $20.0-39.0$ & $30.0-42.0$ & $35.0-60.0$ & \multirow{4}{*}{$\begin{array}{c}\mathrm{F}= \\
160.408^{*}\end{array}$} & \multirow{4}{*}{$<0.001^{*}$} \\
\hline Mean \pm SD. & $29.80 \pm 4.31$ & $36.18 \pm 3.67$ & $45.52 \pm 6.59$ & & \\
\hline Median (IQR) & $30.0(26.50-33.50)$ & $37.50(33.0-39.50)$ & $45.0(40.0-50.0)$ & & \\
\hline $\begin{array}{l}\text { Sig. bet. Grps. } \\
\text { BAND }\end{array}$ & \multicolumn{3}{|c|}{$\mathrm{p}_{1}<0.001^{*}, \mathrm{p}_{2}<0.001^{*}, \mathrm{p}_{3}<0.001^{*}$} & & \\
\hline Min. - Max. & $14.0-30.0$ & $14.0-27.0$ & $10.0-10.50$ & \multirow{4}{*}{$\begin{array}{c}\mathrm{F}= \\
360.475^{*}\end{array}$} & \multirow{4}{*}{$<0.001^{*}$} \\
\hline Mean \pm SD. & $21.10 \pm 4.25$ & $17.23 \pm 2.28$ & $10.28 \pm 0.25$ & & \\
\hline Median (IQR) & $22.0(18.0-24.0)$ & $17.0(16.0-18.0)$ & $10.50(10.0-10.50)$ & & \\
\hline Sig. bet. Grps. & \multicolumn{3}{|c|}{$\mathrm{p}_{1}<0.001^{*}, \mathrm{p}_{2}<0.001^{*}, \mathrm{p}_{3}<0.001^{*}$} & & \\
\hline
\end{tabular}

There was significant difference between three studies groups according to platelet,hemoglobin, hematocrit and Band. table 2

IQR: Inter Quartile Range

F: F for ANOVA test, Pairwise comparison bet. each 2 groups was done using Post Hoc Test (Tukey)

$\mathrm{H}$ : $\mathrm{H}$ for Kruskal Wallis test, Pairwise comparison bet. each 2 groups was done using Post Hoc Test (Dunn's for multiple comparisons test)

40 cases $(40 \%)$ had negative blood culture, and 60 cases $(60 \%)$ had positive blood culture fig. (1).

There was Statistically significant difference between three studies groups according to uTREM1, figure 2

The diagnostic performance of UTREM1 in detection of positive blood culture, uTREM1 could $\mathrm{p}$ : $\mathrm{p}$ value for comparing between the studied groups $\mathrm{p}_{1}$ : $\mathrm{p}$ value for comparing between Positive blood culture and Negative blood culture

$\mathrm{p}_{2}$ : $\mathrm{p}$ value for comparing between Positive blood culture and Control

$\mathrm{p}_{3}$ : $\mathrm{p}$ value for comparing between Negative blood culture and Control

*: Statistically significant at $\mathrm{p} \leq 0.05$

predict positive blood culture with $\mathrm{AUC}=0.999$ ( $\mathrm{p}<0.001)$, CI (0.990-1). At a cut-off value $>72 \mathrm{pg} / \mathrm{ml}$, sensitivity was $98.33 \%$, specificity was $95 \%$, PPV was $96.7 \%$, and NPV was $97.4 \%$. figure 3 .

\section{Blood culture}

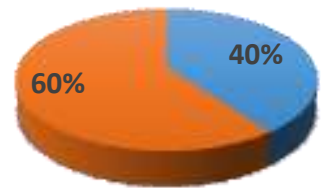

negative Positive

Fig. (1) Distribution of the studied cases according to blood culture. 


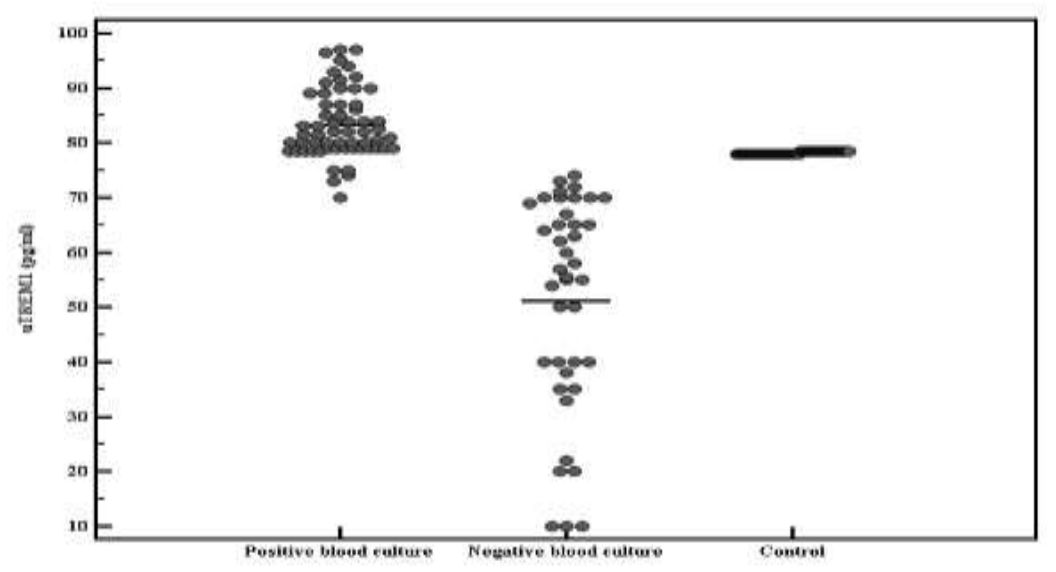

Fig. (2) Comparison between the three studied groups according to uTREM1

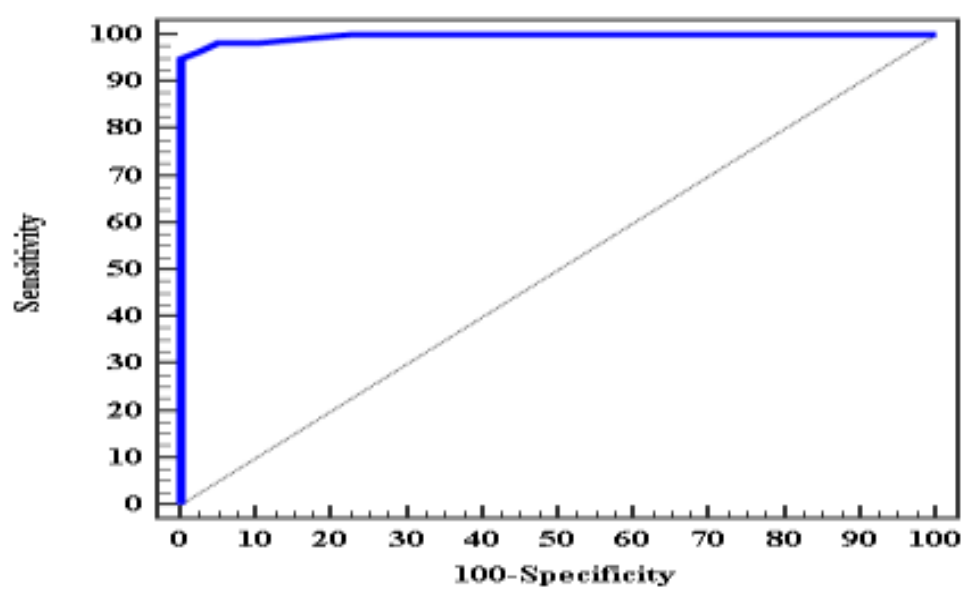

Fig. (3) ROC curve for uTREM1 to diagnose positive blood culture (n=60/100).

\section{Discussion}

In this study, the Positive cultures group: 18 cases ( 30 percent) have had nothing by oral, eight cases $(13.3 \%)$ have had artificial feeding, and in the Negative cultural group 34 cases $(56.7 \%)$ have had breast feeding; 13 cases $(32.5 \%)$ have nothing by oral, 14 cases $(35 \%)$ have artificial feeding, and 13 cases $(32.5 \%)$ have breast feeding. Although all newborns were in the control group with breast feeding, there was a significant difference between feeding groups. Comparison of three groups examined using vital signs; a substantial temperature, heart rate, respiration rate and blood pressure difference between groups $(\mathrm{p}<0.001$, each).

The mean TLC for positive culture groups in this research was $9,17 \pm 4,68$ compared with the negative crop group $8,34 \pm 1,85$ and in controls $8,20 \pm 1,02$, $\mathrm{p}=0,844$. In the positive culture group the mean band cells were substantially higher $21.10 \pm 4.25$, compared with $17.23 \pm 2.28$ in the negative cultures and $10.28 \pm$ 0.25 in checks, $\mathrm{p}<0.001$.

In our findings[9] we agreed with the research, because white blood cell count, neutrophil count and CRP in suspected neonates were significantly higher compared to the equivalent control values $(\mathrm{P}=0.018$,
0.007 and 0.003, respectively). And, in [10] research of 115 children, all sepsis/baacteremia patients showed substantially increased WBC levels $(17.94 \pm 10.04 \pm$ $109 / \mathrm{L}$ vs 10.42 , respectively $\pm 4.21 \pm 109 / \mathrm{L} ; \mathrm{p}<0.001)$, and the number of neutrophils $(10.93 \pm 8.03 \pm 109 / \mathrm{L}$ versus $5.08 \pm 3.42 \pm 109 / \mathrm{L} ; \mathrm{p}<0.001)$. In addition[11] patients with confirmed sepsis were found to have WBC greater than 26000 compared to negative WBC diagnosis $<15500$.

Other researchers[12] have, on the other hand, found the association between low numbers of white blood cells, low absolute neutrophil levels, and high immature to total neutrophils with an increased risk of infection (OR: 5.38, 6.84, and 7.97, respectively). And the platelet finding was less useful to establish the EONS assessment, with the chance of infection with low platelet counts being smallly increased. Specificity and negative forecasting scores were high in the Hornik research (73.7-99.9 and >99.8\%). However, the sensitivities for all the blood cell counts tested were modest (0.3-54.5 percent).

The mean platelet count for the positive culture group was substantially lower in this research than in the negative culture group $(276.4 \pm 72.40)$ and in the controls $\mathrm{p}<0,001(364.9 \pm 73.13)$. 
Sepsis was often linked with Thrombocytopenia and several studies showed a bad prognosis[10, 11, 13].

Similar studies[14],[15] also concurred that decreased platelet number is linked with sepsis. This may be due to direct toxic platelet damage, megakaryocytic suppression, increased peripheral consumption as in DIC, or a rise in the platelet immunoglobulin level. Another research[16] has shown that thrombocytopenia in infants with sepsis is consistently linked to a poor outcome.

In this research, the mean number of haemoglobin in the positive culture group was considerably lower than in the negative culture group, $10.0 \pm 1.84$, and $14.96 \pm 1.22$ in the controls, $\mathrm{p}<0.001$. In positive culture groups, the mean hematocrit level was substantially lower in a group of $29.80 \pm 4.31$, compared to $36.18 \pm$ 3.67 , and $45.52 \pm 6.59$ in controls, $\mathrm{p}<.001$.

According to the previous studied[17], the mean $\mathrm{Hb}$ in sepsis was $(10.561 \pm 2.975 \mathrm{gm} / \mathrm{dl})$ and substantially lower than in non-sepsis group $(14.132 \pm 1.587 \mathrm{gm} / \mathrm{dl})$ $(p<0.001 *)$ And it was also acknowledged that the mean $\mathrm{Hb}$ of the patients was substantially lower in other trials than that of the control group[18],[19]. Sepsis may lead to anaemia due to malfunction of the bone marrow or bleeding (petechiae, purpura, seeping) and haemorrhage [20]

In this research, the positive CRP was 57 instances (95\%), compared to 16 cases $(40 \%)$ of the negative culture group. Similarly,[11] noted that CRP in positive blood cultured patients is significantly greater than in those with negative cultures $(\mathrm{p}<0.001)$. Among the 188 neonates hospitalised with suspected EONS, in 160 [85.1 percent] instances the CRP level was positive [>6 $\mathrm{mg} / \mathrm{L}]$;

While other scientists[17], As for positive instances of septic sepsis in blood culture, only 80 per cent had positive ( $>6 \mathrm{mg} / \mathrm{dl}$ ) CRP, and approximately 20 per cent had negative CRPs while exhibiting sepsis and positive blood culture for the organism, which indicates that the CRP is extremely sensitive, non-sepsis acute phase reactant. Sensitivity, specificity, PPV, CRP NPV (79 percent , 25 percent , 79 percent , 24 percent respectively).

In this research, the mean uTREM 1 was $83.28 \pm$ $6.17 \mathrm{pg} / \mathrm{ml}$, compared to $51.19 \pm 19.47 \mathrm{pg} / \mathrm{ml}$ for positive culture, and $\mathrm{p}<0.001$ was $78.22 \pm 0.25 \mathrm{pg} / \mathrm{ml}$ in controls.

This has been in line with Alkan et al. [8], urine sTREM-1 levels in the culture-proven group have been substantially higher $(115.2 \pm 38.9 \mathrm{pg} / \mathrm{mL})$ compared with the suspected sepsis group $(66.8 \pm 32.4 \mathrm{pg} / \mathrm{ml})$.

Our research is the second to measure TREM-1 urine; although prior studies have evaluated the sTREM-1, which suggests that TREM-1 levels should be determined as a possible diagnostic tool for infections in children. As was the case in [7] in the study of Circulating soluble triggering receptor, expressed in neonatal sepsis as a diagnostic and prognostic marker for myeloid cells-1 (sTREM-1) the Baseline's sTREM-1 levels were significantly raised, compared to controls $(162,2 \pm 61 \mathrm{pg} / \mathrm{mL})$, with no significant differentiation between the two septic groups in culture-proven levels $(1461.1 \pm 523 \mathrm{pg} / \mathrm{mL})$. Cultural positive or negative preterm newborns were substantially greater than full-term neonates for sTREM-1. In early Sepsis neonates, STREM-1 was substantially greater than late Sepsis and linked with high mortality. STREM-1 reduced markedly 48 hours after antibiotic treatment compared to baseline or levels in newborns with consistently positive crops.

And [22] those with questionable LOS and 22 with culturally-positive LOS examined blood levels sTREM1 and interleukin-6 in 31 newborns. They discovered that levels of Blood STREM-1 led to early identification of infected newborns.

Another research conducted in children by [23] examined whether sTREM-1 is detectable in urine samples from urinary tract infected children and in healthy children. In the current research, all patients (healthy and sick) exhibited TREM-1, but the diseased children had TREM-1\%>10\%, while in the noninfected group, only $35 \%$ showed comparable levels.

In this research, the ROC courve was made to evaluate the diagnosis of UTREM1 for the detection of positive blood culture, uTREM1, with AUC $=0.999$ ( $\mathrm{p}<0.001)$, CI, for positive blood culture (0.990-1). With a cut-off value of $>72 \%$, sensitivity was $98.30 \%$, specificity was $95 \%$, PPV was $96.7 \%$ and NPV $97.4 \%$.

This was compared with [24] (Alkan et al., 2018b), a urinary STREM-1 curve analysis was conducted. For urine sTREM-1, the AUC was 0.87. The sensitivity of $78.5 \mathrm{pg} / \mathrm{mL}$ with a cut-off point was 0.78 with a positive predictive value of 0.68 and 0.94 with a negative predictive value.

A meta-analysis[24] was conducted of all 73 papers. Thirteen trials have met the criteria for inclusion (980 patients, 557 bacterial infection, 423 non-bacterial infections); overall prevalence was $56.8 \%$. The global sensitivity was 0,82 (95\% confidence interval CI, 0,68$0,90)$, specificity was $0.86(95 \% \mathrm{CI}, 0,77-0,91)$, the Positive Way Probability Ratio (PLR), 5,66 (95\% CI, $3,41-9,38)$, the NLR was $0,21(95 \%$ CI, 0,12-0.40) and the diagnostic odds ratio (DOR) was 26,35 (95\% CI, 10,32-67,28). The area under the Summary Recipient Operator Characteristic (SROC), with a Q-point value of 0.84 , was 0.86 (95\% CI, 0.77-0.91). The sensitivity of the STREM-1 test for diagnosis was poor $(0.18,95 \%$ CI, 0.05-0.51).

A study [25] on the diagnostic usefulness of urine sTREM-1 for identifying early sepsis, severity, pronostic, and subsequent acute kidney damage was conducted in people. The research revealed that the STREM-1 urine test is more sensitive than the WBC count, CRP and procalcitonin levels for early identification of sepsis and for a dynamic severity and prognosis evaluation. Furthermore, the urine sTREM-1 cut-off was $69.04 \mathrm{pg} / \mathrm{mL}$ with sensitivity of 0.94 and 0.76 specificity.

[26] urinary sTREM-1 level was tested and found to vary from $11.2 \mathrm{pg} / \mathrm{mL}$ to $380.9 \mathrm{pg} / \mathrm{mL}$, with an 
average value of $102.9 \mathrm{pg} / \mathrm{mL}$. The cut-off value for urine STREM-1 was determined as $90 \mathrm{pg} / \mathrm{mL}$ in their research.

Finally, TREM-1 is an essential receptor for the innate inflammatory response and septic tissue[7]. In clinical practise, the data provided in this research supports the utility of uTREM-1 measurement. The actual therapeutic benefit of the UTREM-1 trial is clear, which enables the physician to retain empirical medications until cultures are obtained and thus eliminate needless antibiotic exposure of the patient. Further research will be required as to whether the uTREM-1 advice can decrease antibiotic usage, and further prospective studies will be needed to evaluate the efficacy of uTREM-1 in other kinds of illness.

\section{Conclusion}

TREM-1 is a key receptor for the innate inflammatory and septic response. Our findings revealed that urine STREM-1 levels in culturallyproven septic sepsis were substantially greater than in culture-negative sepsis in LOS newborns. Our findings support the use of UTREM-1 as a potentially simple and accurate diagnostic for newborn sepsis in anticipation of results from culture and results.

\section{References}

[1] I. O.Odabasi and A. Bulbul, "Neonatal sepsis," Med. Bull. Sisli Etfal Hosp.,vol.54,PP.142, 2020.

[2] M.Ershad, A.Mostafa, M.Dela Cruz, and D.Vearrier, "Neonatal Sepsis," Curr. Emerg. Hosp. Med. Rep., vol. 7, pp. 83-90, 2019.

[3] A.Zea-Vera and T.J.Ochoa, "Challenges in the diagnosis and management of neonatal sepsis," J. Trop. Pediatr., vol. 61, pp. 1-13, 2015.

[4] A.L.Shane and B.J.Stoll, "Neonatal sepsis: progress towards improved outcomes," J. Infect., vol. 68, pp. S24-S32, 2014.

[5] S.Gibot, A.Cravoisy, B.Levy, M.-C.Bene, G.Faure, and P.-E.Bollaert, "Soluble triggering receptor expressed on myeloid cells and the diagnosis of pneumonia," N. Engl. J. Med., vol. 350, pp. 451-458, 2004.

[6] C.Cao, J.Gu, and J.Zhang, "Soluble triggering receptor expressed on myeloid cell-1 (sTREM1): a potential biomarker for the diagnosis of infectious diseases," Front. Med., vol. 11, pp. 169-177, 2017.

[7] A.A.M.Adly, E.A.Ismail, N.G.Andrawes, and M.A.El-Saadany, "Circulating soluble triggering receptor expressed on myeloid cells1 (sTREM-1) as diagnostic and prognostic marker in neonatal sepsis," Cytokine, vol. 65, pp. 184-191, 2014.

[8] S.Alkan Ozdemir, E.Arun Ozer, O.Ilhan, and S.Sutcuoglu, "Can neutrophil to lymphocyte ratio predict late-onset sepsis in preterm infants?," J. Clin. Lab. Anal.,vol.32,pp.e22338, 2018.
[9] J.Du, L.Li, Y.Dou, P.Li,R.Chen, and H. Liu, "Diagnostic utility of neutrophil CD64 as a marker for early-onset sepsis in preterm neonates," PLoS One, vol. 9, pp. e102647, 2014.

[10]E. Tamelytė, G. Vaičekauskienè, A. Dagys, T. Lapinskas, and L. Jankauskaite, "Early blood biomarkers to improve sepsis/bacteremia diagnostics in pediatric emergency settings," Medicina (B. Aires)., vol. 55, pp. 99, 2019.

[11]E. Saboohi, F. Saeed, R. N. Khan, and M. A. Khan, "Immature to total neutrophil ratio as an early indicator of early neonatal sepsis," Pakistan J. Med. Sci., vol. 35, pp. 241, 2019.

[12] C. P. Hornik et al., "Use of the complete blood cell count in early-onset neonatal sepsis," Pediatr. Infect. Dis. J., vol. 31,pp. 799, 2012.

[13] S. H. Arif, I. Ahmad, S. M. Ali, and H. M. Khan, "Thrombocytopenia and bacterial sepsis in neonates," Indian J. Hematol. Blood Transfus., vol. 28, pp. 147-151, 2012.

[14] M. Smertka et al., "Serum and urinary NGAL in septic newborns," Biomed Res. Int., vol. 2014, pp. 54-61, 2014.

[15] S. Boseila, I. Seoud, G. Samy, H. El-Gamal, T. S. Ibrahim, and A. Ahmed, "Serum neopterin level in early onset neonatal sepsis," J Am Sci, vol. 7, pp. 343-352, 2011.

[16] G. Abdel-Hakim, N. Shehata, W. AbdelHameed, and N. Abdel-Wahab, "Cord Blood Interleukin-6 as a Predictor of Early Onset Sepsis in High Risk Neonates," Ann. Neonatol. J., vol. 1, pp. 38-48, 2019.

[17] S. M. HAMAM, M. SHIMAA, M. HAMED, and S. MOHAMED, "Incidence of Neonatal Sepsis and the Causative Organisms in Neonatal Intensive Care Unit of Tanta University Hospital,” Med. J. Cairo Univ., vol. 87, December, pp. 5323-5332, 2019.

[18]M. M. Shalaby, A. A. Sobeih, W. E. Abdulghany, E. G. Behiry, Y. M. Ismail, and M. A. Abd-El-Aziz, "Mean platelet volume and serum uric acid in neonatal sepsis: A casecontrol study," Ann. Med. Surg., vol. 20, pp. 97-102, 2017.

[19] M. Makkar, C. Gupta, R. Pathak, S. Garg, and N. C. Mahajan, "Performance evaluation of hematologic scoring system in early diagnosis of neonatal sepsis," J. Clin. Neonatol., vol. 2, p. 25, 2013.

[20]Z.Tigabu Kebede. "Hematologic Profiles of Ethiopian Preterm Infants With Clinical Diagnoses of Early-Onset Sepsis, Perinatal Asphyxia, and Respiratory Distress Syndrome," Glob. Pediatr. Heal., vol. 7, pp. 2333794X20960264, 2020.

[21] W. A. Seliem and A. M. Sultan, "Etiology of early onset neonatal sepsis in neonatal intensive care unit-Mansoura, Egypt," J. 
Neonatal. Perinatal. Med., vol. 11, pp. 323330, 2018.

[22]K. Sarafidis et al., "Diagnostic utility of elevated serum soluble triggering receptor expressed on myeloid cells (sTREM)-1 in infected neonates," Intensive Care Med., vol. 36, pp. 864-868, 2010.

[23] E.Sierra-Diaz, A. Bravo Cuéllar, P.C.Ortiz Lazareno, M.García Gutiérrez, H. F. Georgina, and R. Anaya Prado, "Urine TREM-1 as a marker of urinary tract infection in children," J. Int. Med. Res., vol. 45, pp. 631-638, 2017.

[24] S.Alkan Ozdemir, E.A.Ozer, O. Ilhan, S.Sutcuoglu, and M.Tatl, "Diagnostic value of urine soluble triggering receptor expressed on myeloid cells (sTREM-1) for late-onset neonatal sepsis in infected preterm neonates," J. Int. Med. Res., vol. 46, pp. 1606-1616, 2018.

[25] L.Su. "Diagnostic value of urine sTREM-1 for sepsis and relevant acute kidney injuries: a prospective study," Crit. Care, vol. 15, p. R250, 2011.

[26] C. Palmiere, D. Bardy, P. Mangin, and M. Augsburger, "Value of sTREM-1, procalcitonin and CRP as laboratory parameters for postmortem diagnosis of sepsis,” J. Infect., vol. 67, pp. 545-555, 2013. 